\title{
LA PRAXIS DE LA JUSTICIA CONMUTATIVA. COMPOSICIÓN Y RECOMPOSICIÓN CONCEPTUAL EN LA VIEJA Y LA NUEVA ESPAÑA. (1808-
} $1813) .^{1}$

\section{Esteban Gomez Gaitan ${ }^{2}$}

\begin{abstract}
Resumen
La metodología empleada es, la de la historia conceptual comparada. El objetivo propuesto, problematizar, entre 1808-1813 en los espacios de la Vieja y la Nueva España, las tensiones que traslocan el cambio de significado conceptual de justicia conmutativa y sus formas de compensación, en la coyuntura española, como consecuencia, de la abdicación borbónica en favor de Napoleón, De los resultados obtenidos, se puede establecer que, en la monarquía hispana, tuvo lugar una discusión muy particular, relacionada con el incumplimiento del deber del monarca al pacto original de sujeción. En esta discusión, las tensiones que traslocan el significado del concepto objeto de análisis, permitieron a los actores políticos, en uso del concepto, plantear los de resarcimiento del daño causado por el monarca, al incumplir el pacto social. Lo que permitió la eclosión del laboratorio constitucional y, paulatinamente, la imposición de pesos y contrapesos al monarca en la Vieja España y en el virreinato novohispano, por primera vez, la sustitución del monarca por un triunvirato de representantes populares.
\end{abstract}

Palabras-clave: Justicia conmutativa, pacto social, consentimiento, desigualdad y libertad.

\section{INTRODUCCIÓN}

La cronología natural del concepto de Justicia conmutativa, con las debidas reservas, la podemos

\footnotetext{
${ }^{1}$ La teoría empleada en el presente artículo es, la propuesta por Giuseppe Dusso, en torno al debate sobre el significado conceptual y su aplicabilidad, en la vida político, jurídico y social, en su dimensión crítica. Así como, en la propuesta de integración de: Koselleck, respecto a la Sattelzeit, para la época moderna a partir del siglo XVIII y de Otto Brunner, la Trennung, con el hecho del desfase del nacimiento del concepto y la inmediata realidad histórica-jurídico-político del concepto de justicia conmutativa. ${ }^{1}$ Interpretación que se efectúa, a partir del derecho natural racionalista y la doctrina del pacto social, que adhiere a los conceptos nuevos elementos, señalan nuevas cosas o representan otras, lo que determina su significado. La metodología utilizada en la construcción de este trabajo es, la de la historia conceptual comparada, propuesta por Javier Fernández Sebastián. Método en el que aparte de efectuar un recorrido cronológico del concepto de justicia conmutativa, en su versión coyuntural de justicia de la causa, y sus usos provocados por las tensiones causadas en la coyuntura que, para construir argumentos de legitimación, se le atribuyeron en la Vieja y la Nueva España, por actores con posicionamientos ideológicos diversos (Fernández, 2009). El Objetivo planteado es problematizar las tensiones que traslocan el cambio de significado conceptual de justicia conmutativa, en la coyuntura española, como consecuencia de la abdicación borbónica en favor de Napoleón. En los espacios de la Vieja y la Nueva España, entre 18081813. Bajo los referentes de análisis en el espacio de la Metrópoli: Consentimiento/no consentimiento y patriotismo. En el virreinato novohispano: Estaticidad de las autoridades virreinales, así como, Pueblo-Nación principal y otro subordinado, desigualdad en la representación política y libertad.

${ }^{2}$ Posdoctoral adscrito al programa de Maestría en Historia. Estudios Interdisciplinarios, de la Universidad de Guanajuato, México, becado por el Consejo de Ciencia y Tecnología. E-mail: esteban_gaitan@hotmail.com
} 
encontrar en el mundo occidental desde Aristóteles, en su Ética a Nicómaco. Por establecer, de manera arbitraria, el origen de una definición del concepto en el mundo occidental, el cual regula los modos de trato observando el principio de igualdad, entre lo que uno debe recibir y lo que uno hace. ${ }^{3}$ Como afirmará Elías Palti, se debe recordar que, "en el pensamiento de este pensador griego, no había un concepto de lo político, Para los antiguos era difícil entender entre lo político y lo social”. ${ }^{4}$ A partir de la escolástica, se resolvían problemas políticos, mediante la filosofía griega y romana. Hacía 1521, al vencer el monarca en la guerra de comunidades de Castilla, colocaba su poder material por encima del poder social. Sin embargo, la evolución de las ideas acerca del poder político de las comunidades continuaría su perfeccionamiento durante tres siglos, sino de manera material, si en el campo de las ideas y la forma de regeneración de las instituciones hasta que eclosiono en la primera década del siglo XIX.

A partir del siglo XVIII, ese espacio lineal, continuo y homogéneo del concepto ya no puede ser tomado en cuenta. El concepto adquiere su significado en un plano de apariencias y existencias en la relación política entre el monarca y sus súbditos. ${ }^{5}$ Hablar de igualdad y proporcionalidad en el contrato original de sujeción o pacto social, hace referencia a las obligaciones y cargas contractuales de las partes, quienes, otorgando su consentimiento, se sujetaban al mismo. El monarca en sus deberes soberanos, tenía la obligación, entre otras, de cumplir con el pacto establecido entre él y sus súbditos, de procurar leyes suaves, en beneficio de la colectividad, debía buscar ante todo la seguridad y felicidad del pueblo, esto era, para Thomas Hobbes, lo que se llamaba justicia conmutativa. ${ }^{6}$ De esta manera el gobernante no podía alterar el pacto sin el consentimiento de la persona o asamblea elegida por todos (Hobbes, 2011).

Sin embargo, en la primavera de 1808, surge una tensión institucional al seno de la monarquía española propiciada por la abdicación de los borbones en favor de Napoleón, en la cual, la unidad cognitiva de significado de justicia conmutativa hace referencia a nuevas cosas, se identificó con el término de justicia de la causa,

\footnotetext{
${ }^{3}$ Aristóteles, Ética a Nicómaco, traducción de Gullach Pales, Francisco, España, Impreso por L. Rubio, 1931, p. 1-6, Recuperado el día 28 de julio de 2016, de la red mundial de la información: http://bibliohistorico.juridicas.unam.mx/libros/2/767/pl767.htm ${ }^{4}$ Palti, Elías, Conferencia: "La genealogía de lo político en el mundo hispánico", I Escuela de Verano en Historia Conceptual, modernidades Iberoamericanas, conceptos políticos y sociales, 29 de julio de 2016, Colegio de México, México, 2016.

${ }^{5}$ Palti, Elías, op. cit.

${ }^{6}$ Desde el posicionamiento neo-escolástico en la interpretación de Vitoria, Suárez, seguido con posterioridad por la reforma protestante, el tratado de Westfalia, los tratados de Utrecht, una parte del pensamiento ideológico político acerca del poder soberano pretendió imponerle ciertos límites a la figura real. En un plano ideológico figuraban los pesos y contrapesos del soberano y, la ascensión de los derechos y privilegios de la comunidad irían transformando su propia visión ideológica de las cosas acerca de la libertad e igualdad. En este proceso de transformación doctrinal, el pensamiento expuesto fue madurando sus posicionamientos y uno de ellos fue establecer la obligación del soberano. Al delimitar su potestad se estableció en la ley las prerrogativas y obligaciones del rey con sus súbditos. La ley como máxima expresión de la voluntad general en un plano hipotético obligaba al monarca a garantizar el bien común, entendido esto como el bien general de todos y cada uno de los miembros sociales. Este bien general sólo podía lograrse si se garantizaba la seguridad interna de la sociedad con buenas leyes, el combate al crimen, con la imposición de los castigos y una verdadera justicia distributiva, una economía e industria sana, el crecimiento del comercio que
} 
enunciada según la propia mirada de los actores políticos del momento, que lo empleaban. Adquirió su significado en la praxis política del grupo que lo empleaba, como una necesidad de regeneración política de la monarquía española. Los ostentantes del poder político exteriorizaron diversos referentes simbólicos que aludían al concepto justicia conmutativa. Lo que traslocó su sentido en la representación del deber ser, lo que se aspira a ser y lo que se quería cambiar.

El pacto está roto. El monarca incumplió sus deberes contractuales al entregar la corona a otra casa reinante sin el consentimiento del pueblo. El cambio que origina esta disyuntiva y sus condicionantes no era tarea fácil. En este proceso de cambio, en las fuentes utilizadas en la realización del presente proyecto, existen estructuras visibles del significado conceptual en estudio, como fueron: La promulgación de leyes suaves y justas que garanticen la felicidad del pueblo, pero, también subyacen fuerzas formativas invisibles que permiten ver las cosas tal y como fueron. Las sustancias propias del lenguaje jurídico del pacto original, al que me atrevo a llamar contrato conmutativo, su incumplimiento y las formas de compensar el daño, son las que produjeron esas estructuras. La tensión que surge en los diversos autores de enunciación acerca de la justicia conmutativa traslocó su significado, en su versión coyuntural de justicia de la causa. En el nuevo imaginario de una sociedad dividida, que tiene derecho a un gobierno, hay dos posiciones posibles que producen el cambio de sentido del concepto de justicia conmutativa, en su versión coyuntural de justicia de la causa. Por ello, se hacía necesario apelar a una instancia externa como lo era el concepto de contrato conmutativo para recordar las obligaciones y cargas contractuales, equivalentes y reciprocas, entre las partes y, establecer el sentido de justicia y la referencia a la forma de compensar a la sociedad española de los males que padece la monarquía. ${ }^{7}$

Las preguntas que surgieron, era establecer, qué debemos hacer, el daño ya está hecho; quién debe cumplir el pacto. En los grupos antagónicos, ésta transformación oscila en establecer las formas de compensación del daño causado al pueblo ante la abdicación real que trajo como consecuencia el incumplimiento del pacto original. Entre 1808-1813, bajo las circunstancias de la metrópoli española, los bandos antagónicos tenían respuestas a estas interrogantes, con ciertas similitudes, pero con enormes diferencias en cuanto a su realización.

\section{EL PODER CONSTITUIDO: JOSÉ I DE ESPAÑA}

Por una parte, algunos españoles vieron en las instituciones francesas una oportunidad de modernizar la monarquía; quienes optaron por esta última vía, se les conoció como colaboracionistas, satélites, juramentados y

generaba empleos y mantenía la economía. La seguridad externa frente al ataque de las demás naciones y el fortalecimiento de la soberanía del Estado, todo ello conllevaba consigo la felicidad del pueblo.

${ }^{7}$ Contrato conmutativo. Hace referencia a la relación contractual reciproca en el que s aplican las reglas de justicia, igualdad y proporción que debe haber entre las cosas, cuando se dan unas por otras. 
posteriormente, como afrancesados, es decir, españoles partidarios de Napoleón. ${ }^{8}$ La alternativa afrancesada representada en el Consejo de Castilla, órgano jurisdiccional y gubernativo, se había mostrado complaciente a la voluntad de Napoleón; el plan que tenía este grupo para compensar el daño causado ante el incumplimiento del pacto original que otorga de sentido a la justicia conmutativa, en su versión coyuntural de justicia de la causa era, a través de una reforma desde arriba, establecer un nuevo pacto que garantizará los cambios políticos que requería la monarquía, el evitar los males mayores que pudiera traer consigo el enfrentarse a las tropas francesas, el prescindir de las masas sociales en las decisiones políticas, sanar la administración pública de una monarquía decadente, esto bajo la cabeza de un militar, como Napoleón que dominaba toda Europa, quien tenía un plan para el dominio español y sus territorios ultramarinos, planteaba dentro de sus objetivos, mantener la integridad territorial y la religión católica; restablecer el contenido de las leyes fundamentales, en particular de las Cortes del Reino (Fernández, 2007). En la "Proclama a los españoles" publicada en la Gaceta de Madrid, el 3 de junio de 1808, afirmaba su voluntad de regenerar la vieja monarquía española:

Españoles: después de una larga agonía, vuestra nación iba a perecer. He visto vuestros males y voy a remediarlos ... vuestra monarquía es vieja: mi misión se dirige a renovarla; mejoraré vuestras instituciones y os haré gozar de los beneficios de una reforma sin que experimente quebrantos, desordenes y convulsiones (Bonaparte a, 1808). ${ }^{9}$

Para legitimarse frente al pueblo español, trató de efectuar una serie de medidas para garantizar el ejercicio de su autoridad. En ello, el concepto de justicia conmutativa, significaba, primero lograr el consentimiento de sus súbditos como elemento indispensable de un nuevo contrato original. En esta nueva relación de poder, los españoles, como súbditos, debían obedecer sus mandatos sin oponer resistencia. Al demostrar su quietud, el nuevo gobierno, en un acto de proporcionalidad y reciprocidad, compensando los daños sufridos, podía modificar las leyes e instituciones hispanas. Así mismo, en el manifiesto denominado: "Valerosos españoles", impreso en la Gaceta de Madrid, el 4 de mayo de 1808, al dirigirse al pueblo español, les exponía:

Carlos IV y su hijo están ahora reunidos con el emperador [... ] Napoleón para arreglar la suerte de España. El emperador no ha querido esperar el último resultado de tamaña decisión [...] para que la [nación] propia elija las instituciones políticas que mejor a su índole se adapten $[\ldots]$ (Belliard, 1808). ${ }^{10}$

Napoleón Bonaparte, mediante el discurso impreso trata de insertar en la memoria del pueblo español, que era necesario el cambio al interior de la monarquía española, ante el colapso económico, político y militar en que se encontraban y que existía el temor a la desintegración y desfragmentación, sino se llevaban a cabo estas transformaciones. A través de la Gaceta de Madrid, proyectaba una figura del Salvador, que podía terminar con todos los males; trata de legitimar sus acciones. En búsqueda del consentimiento social en el nuevo pacto de sujeción, implementaba ciertos argumentos como lo eran el mantener la tradición política, integridad territorial y

\footnotetext{
${ }^{8}$ Sobre el tema, ver a ARTOLA, Miguel, Los afrancesados, Madrid, Instituto de Estudios Políticos, 1953

${ }^{9}$ Napoleón Bonaparte, "Proclama a los españoles", Gaceta de Madrid, 3 de junio de 1808: 1-2.

${ }^{10}$ Agustín Belliard, "Valerosos españoles”, Gazeta de Madrid, 6 de mayo de 1808, 434.
} 
la fe católica.

Joaquín Murat, Gran Duque de Berg, Lugarteniente General del Reino y la Junta Suprema de Gobierno, al cumplir los designios del emperador francés, convocó a una reunión en Bayona, entre clero, nobleza y estado general, para tratar la felicidad de España. ${ }^{11}$ En una actitud reformista, los franceses expusieron a los colaboracionistas españoles (afrancesados), todos los males que el sistema político bajo el reinado de Carlos IV les causaba, veían la posibilidad de promulgar una nueva constitución e introducir nuevas instituciones que pusieran fin al régimen borbónico. Se iniciaba el cambio en la política. Para ello, primeramente, procedieron a controlar a la sociedad, trataban ante todo de evitar la intranquilidad popular y la exaltación (Moreno, 1997). Enseguida, la justicia de la causa de este grupo, se vislumbraba en reformar, leyes instituciones y gobiernos; en la conformación de un Consejo de Estado compuesto por seis secciones (Bonaparte b, 1808). El resurgimiento de unas Cortes o Juntas de la Nación, las cuales estuvieron integradas por 172 individuos, divididos en tres estamentos: nobleza, clero y pueblo. Como novedad, por primera vez, se permitía la participación de las provincias de Indias, en la nueva dinastía. Entre las reformas y remedios necesarios para terminar con los males del imperio español, se impuso a José Bonaparte como Rey de España y de las Indias y le otorgó a España su primera Constitución. ${ }^{12}$

El Estatuto de Bayona, anterior a las cortes gaditanas, en un acto de justicia haciendo referencia a la obligación de un rey con su pueblo. En compensación, como remedio de todos los males, le otorgó a los reinos y provincias españolas de América y Asia, igualdad de derechos a la par que la metrópoli. Libertad de culto, industria y comercio. ${ }^{13}$ Cada reino o provincia de América tenía la posibilidad de nombrar diputados. ${ }^{14}$ Dos por Nueva España, Perú, Nuevo Reino de Granada, Buenos Aires, Filipinas, y uno por: Cuba, Puerto Rico, la provincia de Venezuela, Charcas, Quito, Yucatán, Guadalajara, las provincias internas occidentales y orientales novohispanas. ${ }^{15}$ Otra de las formas francesas de cumplir el contrato social en España, era el conceder a sus súbditos españoles una

\footnotetext{
${ }^{11}$ MURAT, Joaquín. Nació en Querey, Francia el 25 de marzo de 1767, murió en Pizzo, el 13 de octubre de 1815. Hijo de un posadero, abandonó sus estudios de teología para alistarse en el ejército tras estallar la revolución francesa. Formó parte de la guardia constitucional de Luis XVI en la que iría ascendiendo en la escala de oficiales. Napoleón solicitó sus servicios para la campaña de Egipto en donde logro su ascenso a General. Se casó con Carolina hermana de Napoleón. En 1808, entra en España con el rango de comandante del ejército. Vivió como protagonista el levantamiento del dos de mayo de 1808. Dio instrucciones para llevar a cabo un castigo ejemplar durante los días 2 y 3 de mayo, incluyendo numerosos fusilamientos sin ningún tipo de juicio. Nombrado rey de Nápoles en 1808. Encerrado, sentenciado y fusilado en Pizzo en 1815.

${ }^{12}$ Una constitución otorgada es una forma de concesión del soberano, según palabras de FERNÁNDEZ GARCÍA, Antonio, Las Cortes y la Constitución de Cádiz, Madrid, Arcos Libros, 2010, p. 44

${ }^{13}$ Artículos LXXXVII-LXXXVIX del Estatuto de Bayona

${ }^{14}$ Artículo XCI del Estatuto de Bayona

${ }^{15}$ Artículo XCII del Estatuto de Bayona. El nombramiento de los diputados debía recaer en los Ayuntamientos elegidos por los Virreyes o capitanes generales de las provincias. Para ser diputado se establecía como requisito ser propietario de bienes raíces y vivir en la provincia en donde fuera elegido. Seis de los diputados de las provincias de América y Asia iban a ser designados por José I como miembros adjuntos en el Consejo de Estado y Sección de Indias.
} 
serie de potestades, los derechos del hombre, libertad, igualdad, seguridad y propiedad. ${ }^{16}$ Paralelamente, instituyó la seguridad del Estado, continuó a perpetuidad la alianza ofensiva y defensiva entre España y Francia, establecida desde el Tratado de San Ildefonso, en 1796 y, la forma de contribución que, cada Nación, tenía para garantizar el pacto. ${ }^{17}$

En contrapropuesta a los designios del emperador, en el verano de 1808, surgió un nuevo aspirante del poder político: el Pueblo-Nación. Las villas, pueblos y ciudades organizadas en juntas provinciales mostraron su rechazo al nuevo monarca. Dentro de las formas de compensar el daño causado en la abdicación de los borbones, que produjo el cambio de sentido de justicia conmutativa a justicia de la causa para este grupo, fue el tomar el camino de las armas. El restaurar a un rey legítimo, que perdió su corona, era su objetivo primordial. Mantener sus bienes una causa de bien común y utilidad pública. Su posicionamiento ideológico se centró en la nulidad de la abdicación a favor del invasor francés, como un acto unilateral por parte del rey, que modificaba el pacto primigenio sin el consentimiento de los súbditos. Las juntas provinciales veían el hecho como una cuestión moral, basada en la conducta del deber, en la conservación y administración de los bienes reales, la integridad territorial y la religión católica. Se vieron en la imperiosa necesidad de justificar su actuar. En ello, tomaron como referencia ideológica la soberanía de la comunidad bajo las libertades que contenían las antiguas leyes medievales españolas, entendidas éstas, como una constitución implícita basada en la costumbre y destinada a reglamentar las relaciones entre el monarca y sus reinos.

Entre 1808-1813, la Corona de Castilla fue sustituida por los representantes de las comunidades reinos, territorios, villas y ciudades, unidas en una causa común. El referente de Nación provocó una apertura que comenzó a cubrir una variedad de posibilidades, cambios y permanencias determinables por un mismo espíritu ideológico en espacios y grupos diversos. En ello, el sentido conceptual de justicia conmutativa, en este grupo político, tiene una recomposición. La forma de compensar el daño reconfigura sus partes. El cambio de sentido del concepto objeto de análisis, se mostraba en la tensión del argumento con el que se respondían que debían hacer en las circunstancias presentes. La obligación de los ostentantes a la dominación política reconfigura sus partes, alude a nuevas cosas al guiarse en dos perspectivas diversas. Entonces se toma en cuenta, si se trataba de una Nación Unitaria o Plural. En la primera acepción se considera a la unidad de la monarquía con un poder central. En cambio, en su segunda concepción, en un nuevo imaginario político, se piensan las partes de un todo, como iguales entre sí, unidas por un mismo rey, las mismas leyes y la religión, pero autónomas y en igualdad de derechos frente a la Metrópoli. El transito del pensamiento a la expresión del nuevo uso del lenguaje social disloca nuevamente el cambio de sentido del concepto de justicia conmutativa en su versión coyuntural de justicia de la

\footnotetext{
${ }^{16}$ Artículos CXXV-CXXXIII del Estatuto de Bayona

${ }^{17}$ Artículo CXXIV del Estatuto de Bayona
} 
causa a la realidad del momento. Estos cambios no se dieron de manera inmediata, en un mismo espacio tiempo, fueron graduales y paulatinos, requirieron previamente la interpretación doctrinal de las teorías acerca de la soberanía.

\section{LA COMPENSACIÓN AL DAÑO CAUSADO EN EL MOVIMIENTO JUNTISTA PENINSULAR}

En esa legitimación constante de los poderes provinciales surgidos en el juntismo, el significado del concepto objeto de estudio se vio enriquecido, al emplear sus referentes simbólicos, como un actuar del pueblo español contra el invasor. ${ }^{18}$ Así al entremezclarse con el concepto de patriotismo, adquirió el sentido de deber y lealtad al rey; representaba el rechazo a Napoleón y sus partidarios. Era un referente social de valores y creencias religiosas, de sublevación, de lucha, de levantamiento, de los pueblos, ciudades y villas, con un enemigo común, el francés, asociado a la irreligión.

Los juntistas mantenían la firme convicción que los franceses no podían efectuar reforma alguna a las instituciones españolas, sabían que sólo el empleo de las armas para desterrar a los aliados traidores, les permitiría que su legítimo rey volviera. En su imaginario, construyeron una nueva legitimidad política que les favorecía, a través del símbolo, la imagen del rey cautivo, les permitía entender que sólo el príncipe de Asturias era quien podía efectuar los cambios que se requerían. La Junta de Asturias, en sus actas expresaba esta idea:

Sin gobierno y en orfandad por el rapto alevoso de su monarca Fernando VII y de toda su dinastía llevado a la fuerza de los dominios de su opresor $[\ldots]$ y amenazados los más caros

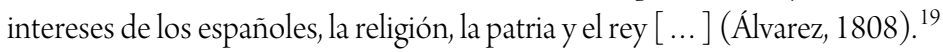

Fernando era considerado, heredero legítimo de la casa real de los borbones, el único que podía garantizar el bien común y felicidad del pueblo español. Pero no todo quedó ahí, posibilitó de manera novedosa el surgimiento de un nuevo sujeto, el Pueblo- Nación, quien tomó la representación política, mientras, desde su mirada, el legítimo soberano estuviera ausente. En ello, se propicia un nuevo cambio de sentido de justicia conmutativa en su versión coyuntural, al ser empleada por actores diversos con metas concretas, en eso, conllevó a una reconstrucción en sus elementos, particularmente, en la figura del titular del poder soberano. A hora, a través de la figura del vasallaje un grupo de actores políticos de nuevo cuño, sin ningún antecedente previo, en ese momento de tensión, al responder a la pregunta, quien debe compensar del daño causado en el incumplimiento del pacto social por parte del monarca. La solución fue nosotros. En ese acto de justicia conmutativa, en igualdad y proporcionalidad a las necesidades de un pueblo oprimido, representan al rey legítimo y administran sus bienes.

\footnotetext{
${ }^{18}$ Las juntas se formaron al margen o frente al poder constituido que ya no existía al estar ausente el rey, lo que produjo una ruptura con las autoridades establecidas bajo las ideas del pactum translaciones (pacto de traslación), siendo depositarias de la soberanía al ya muy clásico poder de las comunidades de los siglos XV y XVI. Un enfrentamiento ideológico entre el poder real y de las comunidades vuelve a resurgir en 1808, sin embargo, no es el absolutismo quien esta ves triunfo.
} 
Pero, el juntismo provincial no era suficiente para lograr sus propósitos. El cumplir las obligaciones del titular del poder político no era tarea fácil y mucho menos dispersas y con órdenes contrapuestas. Para mantener la integridad de la monarquía, las juntas provinciales, se vieron obligadas a crear, la Junta Central Gubernativa del Reino, el 25 de septiembre de 1808, compuesta por 35 miembros ( 17 representantes del estado nobiliario, 6 del eclesiástico y 3 del estado llano). ${ }^{20}$ Este nuevo organismo político siguió el esquema borbónico de gobierno por medio de seis comisiones. Estado, Gracia, Justicia, Guerra, Marina y Hacienda. Al constituirse la Junta Central hubo un nuevo modo de concebir la política, viejas doctrinas tradicionales referentes a la soberanía de las comunidades fueron empleadas con propósitos políticos novedosos, al dejar organizar la nación.

Los miembros que integraban la Junta Central Gubernativa, al efectuar una nueva reinterpretación de las teorías neo escolásticas acerca de la soberanía y al asumir la titularidad soberana, en esa tensión institucional de las autoridades en transición, la unidad cognitiva de significado de justicia conmutativa, vinculada al contexto, produjo un nuevo cambio de sentido, en la propia praxis política, como una necesidad de regeneración. En la forma de compensar el daño causado, le da consistencia al discurso. El transito del pensamiento a la expresión en el uso de este grupo político, disloca el cambio de sentido del concepto materia de análisis. La Junta Central para cumplir el pacto como ente en transición de la titularidad del poder soberano necesitaba legitimarse. El primer paso para lograrlo fue, acotar el poder de las autoridades juntistas regionales. Mediante el Reglamento de Juntas Provinciales, emitido, el 1 de enero de 1809, se limitaba su actuación, éste les prohibía conceder grados militares, civiles o eclesiásticos; redujo sus competencias y facultades, y estableció una administración de corte centralista. Preocupada por la seguridad, estableció un tratado de alianza con Inglaterra, en el interior creó tribunales de vigilancia y seguridad pública para evitar la infiltración afrancesada en la administración naciente (Actas de las Segundas Jornadas sobre la batalla de Bailén y la España Contemporánea, 2001).

La Constitución otorgada en Bayona por el régimen Josefino era uno de los temas a debate que la Junta Central no debía posponer. Al estar roto el pacto y saber quién debía asumir el rol soberano, el responder al que se debe hacer para compensar el daño causado en la abdicación lleva a este grupo a proponer el establecimiento de un nuevo pacto en el que avalaba al pueblo español la organización del gobierno y poner orden a la devastada monarquía. La promulgación de una nueva constitución, era el punto de convergencia con la sociedad de las Españas, la única fuente de legitimidad mediante la cual el poder soberano podía garantizar la felicidad del pueblo con leyes justas y suaves que permitan su seguridad. En el "Proyecto de decreto sobre restablecimiento y convocatoria de Cortes o consulta al país", del 13 de mayo de 1809, seargumentaba:

Sin constitución, toda reforma es precaria, toda prosperidad es incierta; sin ella, los pueblos

\footnotetext{
${ }^{19}$ Ramón Álvarez, Valdés, Memorias del levantamiento de Asturias en 1808, Oviedo, Imprenta del Hospicio Provincial, 1889, 20.

${ }^{20}$ Sobre el tema, ver la obra de MARTÍNEZ VELASCO, A. La formación de la Junta Central, Pamplona, Universidad de Navarra, 1972.
} 
no eran más que rebaños de esclavos, movidos al arbitrio de una voluntad injusta y desenfrenada, siempre; sin ella, las fuerzas de la sociedad entera destinadas a procurar el mayor bien de todos sus miembros, se empleaban exclusivamente en contentar el orgullo y saciar el frenesí de unos pocos o de uno solo (Junta Central Gubernativa del Reino, 1809). ${ }^{21}$

El proyecto en sí, es un ideal que refleja identidad por lo propio. El promulgar una constitución emanada de un pueblo libre debidamente representado por sí mismo, no sometido bajo el yugo de una dominación extranjera. En un sentimiento futuro de realización, se refleja el deseo de la Nación de restaurar las antiguas libertades, para afrontar las circunstancias que atravesaba la monarquía. A partir de las Cortes de Cádiz, esta proposición experimento nuevos cambios, colocó al individuo como centro de todo. No sólo existió la igualdad y libertad de la comunidad para ejercer el control político, sino cualquier ser humano podía acceder y ejercer la representación en el poder soberano.

La opinión pública generada, en torno a quien debería ser el titular del poder político, en una monarquía acéfala, replanteó el deseo de reformar la potestad soberana ante la mala praxis política de Carlos IV. Al respecto los seguidores del grupo juntista, voltearon su mirada a las doctrinas modernas de la división de poderes, con la finalidad de poner una serie de pesos y contrapesos al poder real que evitará los excesos de un solo individuo y la ruina de todo el imperio, como acontecía en España. Así, la primera acción de los diputados de las Cortes de Cádiz, el 29 de agosto de 1811, fue declararse representantes de la Nación y asumir la soberanía.

Al discutirse el artículo 4 de la Constitución gaditana, el diputado por Valencia, Joaquín Lorenzo Villanueva y Astengo, señalaba:

El fin de toda sociedad política lo es el bien de todos los individuos que la componen en orden al bien público de la sociedad y en orden de Dios (Diario de las Discusiones y Actas de las Cortes Extraordinarias de Cádiz 1811-1812).

A partir de ese momento, el gobierno se representaba en una monarquía moderada y hereditaria. La potestad de hacer leyes, residía entre las Cortes y el monarca, y el nombramiento de magistrados y jueces del Poder Judicial serían designados por las propias Cortes. Los límites históricos tradicionales que se atribuían a las leyes fundamentales o pacto de sujeción entre la Comunidad y el Rey, le imponían a este último ciertas acotaciones a sus facultades y condicionaban su poder, le obligaban a tener en cuenta el bien común y la felicidad del pueblo. Ello no implicaba la eliminación radical de la figura real, sino diezmar sus facultades, lo que permitía el desarrollo de la Nación como ente político.

Por otra parte, la Junta Central Gubernativa del Reino tenía la presión de las autoridades constituidas francesas y sus colaboradores, quienes habían enviado una serie de propuestas a América, invitándolos a nombrar representantes al gobierno central. Si los americanos habían rechazado los planteamientos franceses, la Junta

\footnotetext{
${ }^{21}$ Junta Central Gubernativa del Reino, "Proyecto de Decreto sobre restablecimiento y convocatoria de Cortes o consulta al país, 13 de mayo de 1809". http:/ /www.cervantesvirtual.com/obra-visor/proyecto-de decreto-sobre-restablecimiento-y-convocatoriade-cortes-o-consulta-al-pais-13-de-mayo-de-1809--0/html/fff90fc8-82b1-11df-acc7-002185ce6064_1.html\#I_1_ (Consultada el 6 de marzo del 2013).
} 
Central debía actuar, era necesario anular, al contrario, buscar el consentimiento social de la América española. Prácticamente era una cuestión de supervivencia política, perder el nuevo mundo era fracasar en sus propósitos políticos, lo que en pocos años sucedió, por ésta y otras razones. Esto dota de nuevo sentido al concepto de justicia conmutativa, la tensión del consentimiento/ no consentimiento, la presión a la perdida. Fue la necesidad de satisfacer sus anhelos políticos obligo a los juntistas peninsulares a ceder, ante todo debían satisfacer el deseo americano de obtener representación y participar políticamente en las decisiones centrales del gobierno.

La Real Orden del 22 de enero de 1809, promulgada por la Junta Gubernativa del Reino de España e Indias, de iure (de derecho) reconocía las pretensiones americanas a la participación política dentro del gobierno central. Mandato que marcaba un punto de ruptura con el régimen absolutista constituido, era un avance en el reconocimiento al derecho americano de representación política. Por primera vez se establecían elecciones en el continente americano para representantes al gobierno central de la nación. Los Ayuntamientos de las capitales provinciales tenían instrucciones de la forma de elección de sus representantes, debían elegir tres personas de notoria probidad, talento e instrucción, para escoger a una por sorteo. A continuación, el Real Acuerdo elegía a tres de tal grupo para la selección del representante definitivo. Además, los Ayuntamientos dotarín a sus delegados con credenciales e instrucciones (Castel, 1959). El Decreto promulgado por la Junta Gubernativa de España e Indias del 25 de mayo de 1809, extendió los alcances de la representación americana. En el documento se vislumbraba a la nación española en forma unitaria, sin alteración o destrucción del pacto fundacional de manera unilateral. La intención se llevó a la práctica, el convocar a unas Cortes Generales, después de tres siglos de no reunirse.

La representación americana, invitada antes a formar parte del gobierno en el Junta Central, fue un tema muy sensible, puso a reflexionar a los peninsulares. De facto los propios juntistas peninsulares veían a los americanos como inferiores, subordinados producto de la conquista, sus habitantes incultos e incapaces debían obedecer y enviar los metales y recurso para continuar la guerra. La cesión a su participación era un tema de conveniencia, ya que, no podían ceder, frente a los nacidos en el Nuevo Mundo, ciertas potestades ni otorgarles mayor representación de la que ellos tenían. Toda vez que, los virreinatos, reinos, pueblos o las asociaciones de la América española tuvieron un origen y desarrollo distinto a las corporaciones de la metrópoli.

Pero no todo queda allí, este hecho produjo un nuevo cambio de sentido a la justicia conmutativa, la igualdad/desigualdad, la representación política/ no representación y la libertad, proyectan al concepto en espacios diversos, temporalidades distintas y empleado el concepto por actores distintos, con diversas intencionalidades a dotar de un nuevo cambio al significado del concepto objeto de análisis. 


\section{LAS APARIENCIAS PENINSULARES EN EL REINO NOVOHISPANO}

En la Nueva España de 1808, en un espacio territorial distinto y lejano de la Metrópoli, el concepto de justicia conmutativa, al ser empleado en una misma temporalidad y por agentes distintos, hizo referencia a nuevas cosas. Al igual que en la península estaba relacionado con la fidelidad al rey, conservar la religión y la patria, sin embargo, los propios intereses de la práctica política reconstruyeron su significado. Los españoles peninsulares, fuerza política dominante; quienes controlaban en mayor grado las riquezas y la dominación política novohispana, constituían en sí un elemento oculto del concepto de justicia conmutativa, que me atrevo a denominar: Absolutismo local. Para este grupo el concepto objeto de análisis, en su versión coyuntural de justicia de la causa, estribaba en conservar los derechos reales con un interés personal; mantenían la fidelidad al monarca mediante el juramento, sin embargo, mediante el principio: “Obedézcase, pero no se cumpla”, no ejecutaban las disposiciones legales dictadas al centro de la monarquía, al no saber, según sus postulados, por las circunstancias presentes y la enorme distancia existente entre el reino y su metrópoli, si los mandatos aún eran vigentes. En el mayor grado posible evitaban dañar su economía.

Por ende, el concepto de justicia conmutativa al adherirse del concepto moderno de Pueblo-Nación: Principal y subordinado, dotó su significado, en dos posicionamientos referentes al ejercicio del poder político novohispano. Para el grupo a fin al Real Acuerdo, se debían mantener las cosas como estaban. La administración de gobierno ejercida por los peninsulares en América era inalterable. Nada cambió, todo debía permanecer igual en ausencia del rey. En cambio, la postura americana ligada al pensamiento del Ayuntamiento capitalino, advertía el anhelo del americano por dirigir los destinos de la patria, conservar el reino para Fernando VII, preservar la religión, la patria y mantener una relación de autonomía e igualdad entre los gobiernos de América y la Península, cada uno de los cuáles debía preservar los dominios de la monarquía, dentro de sus respectivas jurisdicciones.

La justicia conmutativa de este grupo. era exaltar deberes y sentimientos a la figura de Fernando VII, a quien le rendían juramento; el sentir de fe por el heroísmo de sus hermanos peninsulares, no dudaban de su triunfo ni del retorno del rey, sólo que deseaban administrarle sus dominios novohispanos. Al igual que en la península, declaraban nula la abdicación real, proclamaban que, en ausencia del rey, la soberanía residía en el reino y las diversas clases que lo componían. Pronto requirieron del virrey la convocatoria a una junta, en la capital novohispana, para organizar el nuevo gobierno provisional. El Real Acuerdo, representado por españoles peninsulares, al conocer la propuesta del Ayuntamiento de la Ciudad de México, la rechazaron, ponderaron ante todo sus empleos y la afectación que podía causar a comerciantes, religiosos o criollos acaudalados, residentes en la Nueva España. En el voto del 21 de agosto de 1808, al respecto decían:

En el presente estado de cosas [... nada se ha alterado en orden a las potestades establecidas legítimamente y deben continuar como hasta aquí $[\ldots]$ (Real Acuerdo a, 
$1808)^{22}$

Los oidores no querían diezmar las fortunas de la elite dominante en la Nueva España, Para este grupo, la finalidad soberana era mantener todo igual, esperar las noticias del desarrollo de los sucesos. Toda la estructura administrativa y aplicación legal debía ser conforme a los reglamentos vigentes. En esta corporación yacía un claro disgusto hacía los postulados del Ayuntamiento, les señalaban que los medios planteados no correspondían a la tradición legal española. Refutaban la posibilidad de compartir el poder político entre peninsulares y americanos. Al respecto, el fiscal del crimen, Francisco de Robledo Albuquerque y Gómez argumentaba: 23

Nosotros estamos sujetos a la metrópoli; quien manda en ella con legítima autoridad, nos debe gobernar y no nos es permitido otro sistema (De Robledo Albuquerque y Gómez, 1808)

El pueblo español peninsular en América, muestra un claro sentido de superioridad sobre los pueblos americanos. Existe una diferencia marcada en el sentir de quién debería mandar y quién obedecer. El origen de las provincias españolas y la conformación social novohispana era muy marcado para este grupo. Por lo tanto, en el nuevo mundo, no eran aplicables las leyes de Partida. Ya que, estas leyes fueron promulgadas por y para un pueblo principal, el europeo, no para un pueblo subordinado, quien pretendía usurpar el ejercicio del poder político. Un ejemplo significativo del tema se dio cuando los conjurados peninsulares al mando de Gabriel de Yermo derrocaron al virrey Iturrigaray, la noche del 15 de septiembre de $1808 .{ }^{24}$ Una vez preso el gobernante junto a su familia y los principales regidores de Ayuntamiento de la ciudad de México, los Chaquetas se reunieron en la Sala del Real Acuerdo. ${ }^{25}$ En ese lugar convinieron llamar a gobernar al militar más antiguo; recayó el cargo en el mariscal de campo Don Pedro Garibay, en virtud de la Real Orden, expedida en octubre de $1806 .{ }^{26}$ Después del

\footnotetext{
${ }^{22}$ Voto del Real Acuerdo del 21 de agosto de 1808, sobre la representación del Ayuntamiento del 19 de julio de 1808; en Genaro García, Documentos históricos mexicanos, (México, Museo Nacional, 1910), tomo II, documento 6

${ }^{23}$ DE ROBLEDO ALBUQUeRQUE Y GÓMEZ, Francisco, nació el 13 de marzo en Antequera, Málaga, murió el 19 de noviembre de 1818 en Madrid. Hijo del Licenciado Luis José Robledo de Alburquerque Zayas, Alcalde Mayor de Almendralejo, Extremadura, y Micaela Gómez de Santos. Estudio en el colegio de San Miguel de la Ciudad de Granada "con una beca de leyes". En esa institución obtuvo el grado de bachiller en cánones y después de haber ejercido el tiempo correspondiente en la jurisprudencia fue investido el 4 de octubre de 1768 como abogado de la Real Audiencia de Sevilla. Fiscal del Crimen de México entre 1803-1810.

${ }^{24}$ DE YERMO Y DE LA BÁRCENA, Gabriel, nació el 10 de septiembre de 1757, murió en 1813, fue un rico terrateniente de la Nueva España de origen español, que se convirtió en el líder del movimiento anti independentista y del golpe de estado que derrocó al virrey José de Iturrigaray en 1808. Datos biográficos que se encuentran en Lucas Alamán, Prolegómenos de la independencia mexicana, capítulo seis. Recuperado el día 28 de mayo del 2016, de la red mundial de la información: http://www.antorcha.net/biblioteca_virtual/historia/lucas/indice.html.

${ }^{25}$ Chaquetas, hace referencia al grupo de españoles revolucionarios que depusieron al virrey Iturrigaray. Después del golpe de Estado formaron un batallón con el nombre de Voluntarios de Fernando VII, que adoptaron en su uniforme la chaqueta, para distinguirse de los partidarios del Ayuntamiento de la Ciudad de México, al respecto ver OROZCO Y BERRA, Manuel, Apéndice al diccionario universal de historia y de geografía. Colección de Artículos relativos a la república mexicana, México, Imprenta de J, M, Andrade y F. Escalante, 1856, Volumen II, p. 44.

${ }^{26}$ GARIBAY, Pedro, nació en Alcalá de Henares en 1729, murió en la ciudad de México, el 7 de julio de 1815, fue un administrador colonial español, quincuagésimo séptimo virrey de Nueva España. Llegó a Nueva España en 1764 y desempeñó diversos cargos en el Regimiento provincial de México. Ascendido a coronel en 1738, también fue brigadier y mariscal de campo. El 15 de septiembre de 1808 los españoles de México, dirigidos por el rico comerciante y hacendado Gabriel J. de Yermo, dieron un golpe de estado y
} 
golpe de Estado, los españoles peninsulares trataron de salvar las apariencias, ante todo debían legitimar sus actos. Como hacerlo era lo más importante, planearon y ejecutaron su propósito. Para ello, emitieron una: "Proclama dirigida a los habitantes de México", publicada en la Gazeta extraordinaria de México, el 16 de septiembre de 1808, que vale la pena reproducir en esencia:

... La necesidad no está sujeta a las leyes comunes. El pueblo [principal] se ha apoderado de la persona del Exmo. Sr. Virrey: ha pedido su separación por razones de utilidad y conveniencia general ... (Real Acuerdo b, 1808)

En plena contradicción a sus postulados de mantener el statu quo, los oidores de la Real Audiencia que, con tanto ímpetu se opusieron a la reunión de un Congreso Nacional, atribuían al pueblo sus acciones. En este manifiesto externaban la voluntad del pueblo de poder quitar o poner a los gobernantes que debían dirigirles. Claro que, de una interpretación del eje temático fundamental de análisis, al respecto se desprende que los españoles peninsulares afines a este grupo, en su razonamiento de manera tácita al referirse a pueblo, lo conceptualizaron en un sentido del pueblo principal españoly el pueblo subordinado americano. Otro indicativo del tema lo encontramos en el gobierno virreinal de Don Francisco Javier Lizana y Beaumont, arzobispo de México (1809-1810). ${ }^{27}$ Bajo su mandato, en los últimos días del mes de enero de 1810, llegaron a México, las noticias de Don Pedro de Rivero, secretario de la Junta Central. Personaje quien comunicaba las derrotas sufridas por los ejércitos españoles en el segundo semestre de 1809, y de la excitativa a la colonia para que auxiliará económicamente en la lucha contra los invasores. El arzobispo Lizana se apresuró a reunir armas, pertrechos y recursos como fuente de auxilio a la resistencia peninsular. ${ }^{28}$ Lo que no se pudo cumplir, sino hasta que el Consejo de Regencia, el 7 de mayo de 1810, depositó el poder político. En el Acuerdo de los Oidores, para conservar la tranquilidad de una parte de la monarquía que estaba a punto de romper con la metrópoli. Así constituido el gobierno, la Audiencia, reunió doscientos mil pesos destinados a la adquisición de armas, mandar zapatos a los ejércitos, azufre y plomo para municiones.

El 18 de septiembre de 1810, instalado Francisco Javier Venegas, como virrey, convocó a una junta en el palacio virreinal, en donde le dio lectura a una proclama dirigida por la Regencia a los americanos. ${ }^{29}$ Ahí

\footnotetext{
depusieron al virrey José Iturrigaray. Como sucesor nombraron al mariscal de campo don Pedro Garibay, quien ocupó el cargo hasta el 19 de julio de 1809. Datos bibliográficos que se encuentran en la Biblioteca virtual Miguel de Cervantes. Recuperado el día 28 de mayo del 2016, http:// data.cervantesvirtual.com/person/18887.

${ }^{27}$ DE LIZANA Y BEAUMONT, Francisco Xavier, (1750-1811), nació en Arnedo, La Rioja, España. Quincuagésimo octavo virrey de la nueva España de 1809-1810. Obtuvo el grado de doctor en derecho civil y canónico por la Universidad de Zaragoza, obispo de México, caballero de Carlos III, citado en LÓPEZ CANCELADA, Juan, Sucesos de Nueva España hasta la coronación de Iturbide, estudio introductorio y notas ..., p.107.

28 "Excitativa del arzobispo Don Francisco Javier de Lizana y Beaumont a los habitantes de la Nueva España, 25 de marzo de 1810", en Colección de documentos para la historia de la independencia, tomo II, 27.

${ }^{29}$ VENEGAS, Francisco, Javier, Quincuagésimo noveno virrey de la Nueva España, gobernó de 1810-1813, nombrado por la Regencia, de la que era miembro su tío Francisco Saavedra. A pesar de haber llegado días antes de la insurrección de independencia, pudo formar un ejército y hacer frente a los levantamientos. Ya en España fue nombrado marqués de la reunión en el año de 1816 y capitán de Galicia en 1818, citado en LÓPEZ CANCELADA ..., p. 121.
} 
comunicaba los hechos de armas en la península y les volvía a pedir auxilios para continuar la guerra. También en ese acto, premiaba, con cruces de la orden de Carlos III, con títulos de Castilla y otros honores, a los autores de la prisión de Iturrigaray. ${ }^{30}$ Otro motivo de agravios que servirá de justificación a los insurrectos novohispanos que recién iniciaban la lucha armada.

\section{LA IMPRESIÓN DE PÉRDIDA Y LAS ACCIONES DEL ADVERSARIO}

En pocos años, (1808-1814), las prácticas locales junto a las decisiones del centro de la dominación española tuvieron repercusiones en la periferia. Las ideas políticas y la formación de un nuevo centro de poder político transitaron del pensamiento a la expresión. No es casualidad que, al adaptarse las prácticas políticas tradicionales a propósitos políticos novedosos en el espacio americano, el alcance del concepto de justicia conmutativa comenzó a cambiar. La destitución de Iturrigaray y los principales miembros del cabildo en 1808, no apaciguaron la necesidad de conformar un Congreso Nacional americano.

A partir de 1810, un sentido de perdida, de la parte peninsular de la monarquía, ocasionada por las desastrosas derrotas sufridas por los leales patriotas peninsulares, asociado al descrédito institucional peninsular y virreinal, la desigualdad novohispana en la representación soberana, provocó que un grupo de criollos insatisfechos, adherentes a las propuestas del Cabildo de la ciudad de México, comenzaran a conjurar contra de la dominación política peninsular en América, al igual que en la península se preguntaron: Roto el pacto, qué debían hacer, de forma secreta discutían los principales acontecimientos de la monarquía y sus repercusiones en el reino novohispano; como cumplir la obligación soberana a la par y en proporcionalidad a las cosas. Las formas de compensar el daño, formaron planes y propuestas tendientes a la organización del gobierno comenzaron a tener forma y el anhelo de realización. Otra cuestión era, quién lo debe hacer, en la respuesta existe un nuevo cambio de sentido al concepto de justicia conmutativa en su versión coyuntural al término de justicia de la causa, la tensión que causa, al interior del concepto la desigualdad, la falta de representación proporcional llevan a los insurrectos a plantearse una finalidad, para conseguir la felicidad y seguridad del pueblo novohispano, no debían apoyar un nuevo régimen político en la península, sino formar uno propio en la Nueva España, que gobernará en nombre de Fernando VII, preservará la religión y la patria. Al respecto Miguel Hidalgo y Costilla, en la Proclama a la Nación Americana, del 21 de noviembre de 1810, refería: ${ }^{31}$

\footnotetext{
30 "Nota de las gracias que el Rey nuestro Señor Don Fernando VII, y en su nombre el Consejo de Regencia de España e Indias, ha concedido a diferentes sujetos de la capital que se han distinguido por sus donativos, préstamos y noble entusiasmo por la justa causa de la patria, del rey y la religión”, en GARCÍA, Genaro, Colección de documentos para la historia de la independencia, tomo II, documento 59.

${ }^{31}$ HIDALGO Y COSTILLA GALLAGA MANDARTE Y VILLASEÑOR, Miguel Gregorio Antonio Ignacio, también llamado El cura Hidalgo; nació en San Diego Corralejo, Guanajuato, 1753 y murió en Chihuahua, 1811. Patriota mexicano que inició la lucha por la independencia. En 1773 se graduó como bachiller en filosofía y teología, y obtuvo por oposición una cátedra en el
} 
[... ] Para la felicidad del reino, es necesario quitar el mando de las manos de los europeos. Esto es todo el objeto de nuestra empresa [ ... ] (Hidalgo a, 1810)

De la misma manera, el padre de la patria, en el Manifiesto de la autodeterminación de las naciones, dado en Guadalajara, diciembre de 1810, afirmaba:

[...] Cuando vuelvo la vista por todas las naciones del universo y veo que quieren gobernarse por individuos de su misma nación $[\ldots]$ el francés quiere ser mandado por francés, el inglés por inglés, el italiano por italiano [...] (Hidalgo b, 1810)

El criollo insurrecto no buscaba su participación política en el gobierno peninsular, quería asumir la titularidad soberana y compensar los daños causados con la abdicación desde su propio sentir americano. Para este grupo, el lugar de nacimiento jugó un papel fundamental, al sostener que el gobierno de una provincia o reino debía ser ejercido por los individuos nacidos allí, en su patria. La igualdad de representación en el proyecto alterno de nación, lo constituía la aspiración de los americanos para formar un gobierno, al igual que sucedía en la metrópoli, disloca el sentido de justicia conmutativa. Dos naciones hermanas unidas por el mismo rey y una misma religión integradas en una federación de estados podían ejercer actos de soberanía en sus respectivos espacios territoriales. El pueblo peninsular no permitió a los pueblos americanos formar su propio gobierno. En ese momento, el derecho no garantizaba al novohispano la libertad para gobernar sus dominios. ${ }^{32}$ La búsqueda la tuvieron que hacer por el camino de las armas. Francisco Severo Maldonado, en el manifiesto dirigido A todos los habitantes de América, refería: ${ }^{33}$

Americanos despierten al ruido de las cadenas que arrastran desde hace tres siglos $[\ldots]$ abran los ojos a sus verdaderos intereses que no los acobarden los sacrificios y privaciones que acarrea toda revolución [ ... (Severo Maldonado, 1810)

El derecho de resistencia era el fundamento que permitía al criollo insurrecto luchar contra la tiranía y el despotismo. De esta circunstancia, ya no se consideraba solo que el rey violo la justicia conmutativa, sino, se cuestionaba la imposición de los españoles peninsulares en el derecho de representación e igualdad americano. La argumentación jurídica había muerto, los argumentos peninsulares hacia el americano eran actos de coacción y sometimiento. En esas condiciones contextuales, la dislocación de la unidad cognitiva de significado motivo de análisis se vio entremezclada con la libertad. La cuál en un acto de justicia conmutativa posibilitaba al rebelde novohispano conformar un nuevo gobierno y una Constitución acorde a sus intereses. En búsqueda de

mismo Colegio de San Nicolás. Miguel Hidalgo se integró activamente en los círculos que cuestionaban el estatus colonial y conspiraban para derrocar al virrey español. Cuando fue descubierta la conjura en que participaba, su firme determinación y su llamamiento a tomar las armas en el llamado Grito de Dolores. Recuperado el día 28 de mayo del 2016, http://www.biografiasyvidas.com/biografia/h/hidalgo.htm.

${ }^{32}$ El concepto de verdadera libertad que, se buscaba en los inicios de la lucha armada no ambicionaba el desprendimiento de la monarquía, era entendido como permitir el comercio, la industria, la minería, el empleo de los criollos y en un plano de inclusión, devolver la tierra a los indígenas.

33 SEVERO MALDONADO, Francisco, nació en Tepic en 1775, murió en Guadalajara en 1832. Escritor y político mexicano. Partidario de la independencia, en 1810 editó en Guadalajara un periódico insurgente, El Despertador Americano, que fue suspendido tras la batalla de Calderón. Paso al bando realista de manera inmediata y en 1811 comenzó la redacción del Telégrafo de Guadalajara. En 1821 fue nombrado diputado a las cortes españolas, pero no llegó a ocupar el cargo. Participó en la redacción del primer proyecto de constitución mexicana. Recuperado el día 28 de mayo del 2016, de la red mundial de la información: http://www.biografiasyvidas.com/biografia/m/maldonado_francisco_severo.htm, 
legitimación para robustecer sus aspiraciones, tomaron como estrategia, la unidad de los americanos en una causa común: El expulsar al peninsular. De ahí que, el camino para conseguirlo fue, establecer un pasado común de sufrimientos entre los pueblos heterogéneos de la Nueva España. Esto otorgaba a su discurso, un sentido de identidad y cohesión.

Al respecto quisiera añadir que, en 1812, José María Cos envió al virrey Francisco Xavier Venegas, su Manifiesto y los Planes de Paz y de Guerra, para terminar con la guerra civil que acaecía en el virreinato. ${ }^{34}$ Cuando este último personaje, en calidad de jefe político de los destinos novohispanos, mandó quemar por mano de verdugo dichas propuestas, tal como lo buscaba, el movimiento insurgente fue legitimado en el derecho natural $y$ de gentes, por las propias autoridades constituidas. Ahora podían los insurrectos establecer en sus argumentos, el derecho de resistencia y el uso de la fuerza para combatir la tiranía que los oprimía. Las fuerzas militares rebeldes encontraron justificación en el derecho para combatir al ejército realista e insertar en la memoria social que sus acciones las efectuaban porque los peninsulares de manera atroz, destruían villas, pueblos y ciudades; mataban a niños, mujeres y ancianos.

En 1813, se planteó por primera vez, en el Congreso de Anáhuac, la separación total de la monarquía. Así, el concepto objeto de análisis se adoptó a propósitos políticos novedosos, el autogobernarse. Los rebeldes mexicanos, conocedores de las discusiones de Cádiz, el principio de división de poderes del constitucionalismo francés; ante los malos tratos y vejaciones coloniales, declararon la independencia nacional. La figura real es sustituida bajo un sistema de pesos y contrapesos, un triunvirato de representantes nacionales que conformaban el poder ejecutivo, cuyos miembros rotarían la presidencia cada tres meses. El poder no se reunía más en una sola persona o corporación, sino entre poderes independientes, bajo los designios de la ley. Para garantizar la seguridad de sus habitantes frente a los peninsulares que les impedían actuar como ente político soberano, la diplomacia jugaba un papel fundamental en la búsqueda de reconocimiento del sumo pontífice y auxilio entre los pueblos principalmente los Estados Unidos.

\footnotetext{
${ }^{34}$ COS PÉREZ, José María, nació en Zacatecas hacía 1770, Hijo legítimo del español Isidro Cos y Matiana Pérez, hizo sus primeros estudios en el Colegio de san Luis de Gonzaga, instituto fundado por los jesuitas. Alumno sobresaliente se ganó una beca de colegial pensionista en el seminario tridentino de Guadalajara. Poco después recibió las ordenes sacerdotales y se inició en la carrera burocrático-administrativa. Vicerrector de su Colegio zacatecano en 1800, a partir de 1802-1810, cura del Burgo de San Cosme. Cos formó parte de la Junta de Zitácuaro, convocada por Ignacio López rayón en 1811. Luego de la expulsión de los insurgentes por parte del ejército virreinal, José María de Cos permaneció al lado de López Rayón, a quien acompañó hasta Sultepec. En ese sitio, Cos editó dos periódicos proclives a la insurgencia, en una imprenta que él mismo construyó. Los nombres de estas ediciones eran El Ilustrador Nacional y el Ilustrador Americano. También en Sultepec escribió su Manifiesto que hacen al pueblo mexicano los representantes de las provincias de América y los Planes de Paz y de Guerra. José María de Cos se acogió al indulto ofrecido por las autoridades virreinales en el año de 1817. Murió en Pátzcuaro, Michoacán en 1819. LEMOINE VILLICAÑA, Ernesto, José María Cos, Escritos Políticos, México, Universidad Nacional Autónoma de México, 1967, XVI-LXX.
} 


\section{LAS COMPENSACIONES DE LOS ACTORES SOCIALES EN EL CAMBIO DE SIGNIFICADO CONCEPTUAL DE JUSTICIA CONMUTATIVA.}

En conclusión, la presente reflexión no fue centrada exclusivamente en las tensiones coyunturales que sufrió el concepto de justicia conmutativa, entre 1808-1813, en los espacios de la Vieja y la Nueva España. A la vez, como propuesta de discusión, en una dimensión crítica, las fuentes permitieron establecer, como en el cambio de significado conceptual los diversos actores políticos, al transitar del pensamiento a la expresión, no sólo reflejaron sus deberes y sentimientos, sino las formas de compensación para resarcir el daño ocasionado a la sociedad, por el incumplimiento de las obligaciones contractuales, en el pacto social de sujeción, pacto primigenio o contrato conmutativo. El problema del significado conceptual de justicia conmutativa, fue resuelto por diferentes actores sociales, en un mismo espacio o en espacio distintos, al responder dos interrogantes: Qué de vemos hacer, cómo debemos hacerlo, quién debe efectuarlo. En que se basaron dichos actores para resolver su problemática presente, al realizar una interpretación jurídica de los elementos que conforman el pacto de sujeción, comprendieron el daño causado a los súbditos, ante el incumplimiento por uno de los contratantes. Esto proyectó el uso conceptual de justicia conmutativa, como una necesidad de regeneración política, en la representación del deber ser, lo que se aspira a ser y lo que se quería cambiar. Los ostentantes del poder político exteriorizaron como referente simbólico el término coyuntural de justicia de la causa que aludía al concepto justicia conmutativa, lo que traslocó su sentido. Juramentados, absolutistas, leales a Fernando VII, liberales, realistas fieles, insurgentes, insurrectos, moderados, etcétera, etcétera. Todos los grupos políticos surgidos en el momento entendían perfectamente quien era su rey legítimo. También sabían que, no se encontraba presente. La incomunicación impedía recibir las órdenes necesaria para actuar en las circunstancias que el pueblo atravesaba por la ocupación de la Metrópoli por fuerzas militares externas. De esta manera un rey legítimo, en sus propias acciones violo el pacto. Era causa de utilidad pública, mantener la unidad, el territorio y la religión. El pueblo requería un gobierno que lo representará. En ello, el concepto de justicia conmutativa sufrió tensiones que cambiaron su significado o hicieron referencia a nuevas cosas. Factores visibles relacionados con la restauración o renovación de la monarquía e, invisibles vinculados con la metamorfosis, entre tradición, transición y modernidad, de acotamiento y sustitución de los poderes soberanos del monarca, proyectaron el concepto de justicia a la celebración de un nuevo pacto social. El poder político no recaía en una sola persona, se planteaban pesos y contrapesos a la figura real. En ese campo tan rico de articulaciones del lenguaje jurídico- político el compensar en justicia conmutativa al pueblo, fue lo que dio paso a la construcción del laboratorio constitucional iberoamericano. La soberanía no descansaba en el monarca, sino en la constitución emanada del Pueblo- Nación. 


\title{
THE PRAXIS OF COMMUTATIVE JUSTICE. COMPOSITION AND CONCEPTUAL RECOMPOSITION IN OLD AND NEW SPAIN. (1808-1813)
}

\begin{abstract}
The methodology used is that of comparative conceptual history. The proposed objective, problematize, between 1808-1813 in the spaces of the Old and New Spain, the tensions translocated change conceptual meaning of commutative justice and forms of compensation, the Spanish situation, as a result, the abdication Bourbons for Napoleon, from the results, it can be established that in the Hispanic monarchy, a particular discussion related to the breach of duty of the monarch holding the original pact took place. In this discussion, the tensions translocate the meaning of the concept under analysis, allowed political actors, in use of the concept, raise the compensation for damages caused by the monarch, by breaching the social pact. Which allowed the emergence of constitutional laboratory and gradually imposing checks and balances to the monarch in Old Spain and New Spain Viceroyalty, for the first time, replacing the monarch by a triumvirate of popular representatives.
\end{abstract}

Keywords: Commutative justice, social pact, consent, inequality and freedom.

\section{BIBLIOGRAFÍA}

ÁLVAREZ VALDÉS, Ramón. Memorias del levantamiento de Asturias en 1808. Oviedo: Imprenta del Hospicio Provincial, 1889, p. 20.

ARISTÓTELES, Ética a Nicómaco. Traducción de GULLACH PALES, Francisco, Madrid: Impreso por L. Rubio, 1931, p. 1-6.

ARTOLA GALLEGO, Miguel. Los afrancesados. Madrid: Instituto de Estudios Políticos, 1953, p. 35.

BELLIARD, Agustín. "Valerosos españoles". Gazeta de Madrid, 6 de mayo de 1808, p. 438.

BONAPARTE, Napoleón. Proclama a los españoles. Gaceta de Madrid, 03 de junio de 1808.p. 1-8.

Comunicado. Gazeta de Madrid, 28 de mayo de 1808, p. 509-510.

CALVO DE ROZAS, Lorenzo. Proposición de Calvo de Rozas de convocatoria de las Cortes y elaboración constitucional. Sevilla: Imprenta de los hijos de J.A.García, p. 1809.

CASTEL, Jorge. La Junta Central Suprema y Gubernativa de España e Indias. Madrid: Imprenta Marte, 1959, p. 73.

CIRCULAR DE LA JUNTA DE MURCIA. Solicitando la formación de la Junta Central de 22 de junio de 1808. Recuperado el día 5 de marzo de 2016 de la red mundial de la información: http://www.cervantesvirtual.com/obra/circular-de-la-junta-de-murcia-solicitando-la-formacion-de-la-juntacentral-murcia-22-de-junio-de-1808--0/. 
DE LIZANA Y BEAUMONT, Don Francisco Javier. Excitativa a los habitantes de la Nueva España, 25 de marzo de 1810. GARCÍA, Genaro. En: Colección de documentos para la historia de la independencia, tomo II, documento 27.

DIARIO DE LAS DISCUSIONES Y ACTAS DE LAS CORTES EXTRAORDINARIAS DE CÁDIZ 18111812. Volumen VIII, p. 99.

DUQUE DE BERG, y Junta Suprema de Gobierno. Representación a Cortes de Bayona. Gazeta de Madrid, 24 de mayo de 1808, p. 490-495.

DUSSO, GIUSEPPE, Historia conceptual como filosofía política, Res pública 1, (1998): 35, 38, 56.

FERNÁNDEZ GARCÍA, Antonio. Las Cortes y la Constitución de Cádiz. Madrid: Arcos Libros, 2010, p. 44.

FERNÁNDEZ SARASOLA, Ignacio. La Constitución de Bayona (1808), Madrid: IUSTEL, 2007, p. 135-136.

FERNÁNDEZ SEBASTIÁN, Javier. Diccionario Político y Social del Mundo Iberoamericano, tomo I, Madrid: Fundación Carolina/Sociedad Estatal de Conmemoraciones Culturales/Centro de Estudios Políticos Constitucionales, 2009, p. 41.

FERNANDO VII, Carlos Borbón, y Antonio Borbón. Renuncia a la corona y sus derechos a ella, Gazeta de Madrid, 20 de mayo de 1808, p. 483

GUERRA, Francois Xavier. "Dos años cruciales (1808-1809)". En.: Modernidad e independencias. Ensayos sobre las revoluciones hispánicas. de Francois Xavier Guerra, México: Fondo de Cultura Económica, 2010, 118-148.

HERNÁNDEZ ENVIS, Luis. Instrumentos de control y represión del régimen patriota: el Tribunal de vigilancia de Madrid y el de Seguridad Pública de Sevilla (1808-1809). En.: Bailén y Guerra contra Napoleón en Andalucía. Actas de las Segundas Jornadas sobre la batalla de Bailén y la España Contemporánea, Jaén: Universidad de Jaén, 2001, p. 173.

HIDALGO Y COSTILLA, Miguel. Proclama a la nación americana, México: Archivo General de la Nación, 1810, ramo Operaciones de Guerra, tomo IV, foja 6

Manifiesto de la autodeterminación de las naciones. En.: Guadalajara, diciembre de 1810. En.: MARTÍNEZ Álvarez, José Antonio. Miguel Hidalgo, documentos por la Independencia. México: H. Cámara de Diputados LVIII Legislatura, H. Congreso de la Unión, 2003, p. 131-132.

HOBBES, Thomas. Leviatán, México: Fondo de Cultura Económica, 201 1, p. 275

JUNTA CENTRAL GUBERNATIVA DEL REINO. Proyecto de Decreto sobre restablecimiento y convocatoria de Cortes o consulta al país del 13 de mayo de 1809. Biblioteca virtual Miguel de Cervantes. Recuperado el día 6 de marzo del 2016 de la red mundial de añ información: http://www.cervantesvirtual.com/obra-visor/proyecto-de-decreto-sobre-restablecimiento-y-convocatoria-decortes-o-consulta-al-pais-13-de-mayo-de-1809--0/html/fff90fc8-82b 1-1 1 df-acc7-002185ce6064_1.html\#I_1_.

LEMOINE VILLICAÑA, Ernesto, José María Cos, Escritos Políticos, México, Universidad Nacional Autónoma de México, 1967, P. XVI-LXX. 
MALDONADO, Francisco Severo. A todos los habitantes de América. Despertador Americano. Seminario patriótico. Correo Político Económico de Guadalajara, 20 de diciembre de 1810, p. 1-10.

MOLINER PRADA, Antonio. El movimiento juntero en la España de 1808". En.:1808: La eclosión juntera en el mundo hispánico, coord. Manuel Chust, México: Fondo de Cultura Económica, 2007, p. 72.

MORENO ALONSO, Manuel, Los españoles durante la ocupación napoleónica. La vida cotidiana en la vorágine: Málaga, editorial Alcázara, 1997, p. 71.

Nota de las gracias que el rey nuestro señor Don Fernando VII. Y en su nombre el Consejo de Regencia de España e Indias, ha concedido a diferentes sujetos de la capital que se han distinguido por sus donativos, préstamos y noble entusiasmo por la justa causa de la patria, del rey y la religión. En.: HERNÁNDEZ Y DÁVALOS, Juan E. Colección de documentos para la historia de la independencia: tomo II, documento 59.

PALTI, Elías, Conferencia: La genealogía de lo político en el mundo hispánico, I Escuela de Verano en Historia Conceptual, modernidades Iberoamericanas, conceptos políticos y sociales, 29 de julio de 2016, Colegio de México, México, 2016

QUINTANA, Manuel José. De los principales sucesos ocurridos en Madrid y en las provincias de España desde octubre de 1807 hasta septiembre de 1808. Semanario Patriótico, 17 de noviembre de 1808, p. 201-203.

Real acuerdo del 21 de agosto de 1808, voto del, sobre la representación del Ayuntamiento del 19 de julio de 1808. En.: GARCÍA, Genaro, Documentos históricos mexicanos, México: Museo Nacional, 1910, tomo II, documento 6. 1808.

Proclama dirigida a los habitantes de México. Gazeta extraordinaria de México, el 16 de septiembre de

ZARATE, Julio, México a través de los siglos, México: Espasa y Compañía, 1884, tomo III, p. 46.

\section{Páginas web consultadas}

http://bibliohistorico.juridicas.unam.mx/libros/2/767/pl767.htm

http://www.antorcha.net/biblioteca_virtual/historia/lucas/indice.html.

http://www.biografiasyvidas.com/biografia/h/hidalgo.htm.

http://www.biografiasyvidas.com/biografia/m/maldonado_francisco_severo.htm.

http://data.cervantesvirtual.com/person/18887

Trabalho enviado em 30 de maio de 2016.

Aceito em 24 de agosto de 2016. 